\title{
ASSESSMENT OF A DRIVER INTERFACE FOR LATERAL DRIFT AND CURVE SPEED WARNING SYSTEMS: MIXED RESULTS FOR AUDITORY AND HAPTIC WARNINGS
}

\author{
Tina Brunetti Sayer \\ Visteon Corporation \\ Van Buren Township, Michigan, USA \\ E-mail: tsayer@,visteon.com \\ James R. Sayer, Joel M.H. Devonshire \\ University of Michigan Transportation Research Institute \\ Ann Arbor, Michigan, USA
}

\begin{abstract}
Summary: Lateral Drift Warning (LDW) and Curve Speed Warning (CSW) systems were developed to address two main critical events in run-off-road crashes, which are road edge departure and excessive speed. The LDW system used a two-stage alert system, with the first stage activating when the driver departed a lane with a dashed boundary and the imminent, or second stage, when departing a lane with a solid boundary. The CSW also employed a two-stage alert, with the level based on the degree of over-speed for the upcoming curve. The haptic modality, in the form of seat vibration, was chosen as the first level warning for both systems, and auditory was chosen as the second or most urgent level. The two systems were installed in a fleet of instrumented vehicles and loaned to 78 randomly selected licensed drivers for approximately 4 weeks. Debriefing questions detailing the driver's experience with the system were administered and analyzed in a two by two design of modality by system. After examination of both the statistical results and the open-ended comments, the question of which modality is most appropriate is still uncertain. Each modality had positive aspects. Haptic does not alert the entire car and participants also considered it less distracting. Auditory provided better recognition between warnings and participants were better able to understand the meaning and the required response for each warning.
\end{abstract}

\section{INTRODUCTION}

Run-off-road crashes account for approximately 1.4 million crashes or over $20 \%$ of all crashes annually (Najm, Sen, Smith, and Campbell, 2003). In these crashes, departing the road edge and control loss are the main critical events (Koopman and Najm, 2002). To address run-off-road crashes, two crash warning systems were developed. The first, Lateral Drift Warning (LDW), was developed to warn drivers about departing the road edge. The second, Curve Speed Warning (CSW), was designed to address control loss due to excessive speed in curves. The LDW system provided two levels of warning: one which warned drivers that they were drifting out of their lane and across a "dashed" lane marking, and one which warned if the driver was crossing a solid lane marking. The CSW system also used a two-stage warning; the level of the warning was based upon the degree to which the driver was approaching an upcoming curve too fast. 
Of the five human senses, there are essentially three modalities available to warn drivers of an impending crash threat: visual, auditory and haptic. The remaining modalities (taste and smell) are not easily adapted to an interface within the driving environment (in which an immediate response is needed). Visual was chosen to be the "redundant" modality; it was presented during both cautionary and imminent warnings on a head-down display. Cautionary warnings for both LDW and CSW also presented to the driver were haptic, in the form of seat vibration. The haptic seat was chosen as the cautionary level of warning because it does not alert the entire vehicle and is therefore less intrusive. As stated in Lerner, Kotwal, Lyons, and Gardner-Bonneau (1996), "The highest level of warning...uses a more urgent and intrusive signal. Cautionary warnings provide the driver with great advanced warning, in a less disturbing form" (p. xiv). For the most urgent level of warning in both systems, when an imminent threat of a crash exists, an auditory warning was chosen.

\section{METHODS}

\section{Participants}

Seventy-eight participants, consisting of three age groups and balanced for gender, took part in the study. All were licensed drivers residing in southeastern Michigan, and were selected at random from driving licensure records. Each participant was loaned an instrumented research vehicle equipped with the LDW and CSW systems for approximately four weeks. During the first week, the LDW and CSW did not provide any warnings to the driver (to provide a baseline). During the remaining three weeks, all warnings were operational. After returning the vehicle, drivers were given a questionnaire detailing their experience with the system.

\section{Research Vehicles}

The research vehicle was a 2003 Nissan Altima SE. An LDW system from AssistWare Technologies was installed in the vehicle. The LDW system used a camera to determine lane position and based warnings on an optical image from the forward scene and other sources of information (i.e., side radar, forward radar, previous road traversals). A CSW system developed by Visteon was also installed in the vehicle. The CSW used a GPS system with a digital map to determine where, on a given road, the driver was located. Warnings were issued when the CSW determined there was an upcoming curve in the intended path and the driver was exceeding the calculated speed for that given curve. Additional data, such as air temperature and the probability of taking a particular road segment, also aided in the determination of when to give a warning. To provide warnings, an InSeat Solutions haptic seat system was installed. Eight DC offset weight motors were embedded in the seat, as shown in Figure 1. The research vehicle also included a premium audio system with eight speakers in the cabin. An intermediary control circuit between the vehicle's radio and amplifier modules allowed the complete control of the audio system's output.

\section{Warning Characteristics}

Each system had two levels of warning: cautionary and imminent. For cautionary warnings, the drivers received haptic warnings in the form of seat shakers located in the seat pan of the driver's seat (Figure 1). A pulse pattern was used for the LDW cautionary warning, which was intended 
to simulate driving over rumble strips localized to the appropriate side of the seat (see Figure 2). For a LDW indicating the crossing of a dashed boundary to the drivers left, motors 5 and 6 were activated; LDWs to the right used motors 3 and 4. For CSW cautionary warnings, a steady pulse was used (see Figure 3) and was localized to the front of the seat via motors 4 and 5.

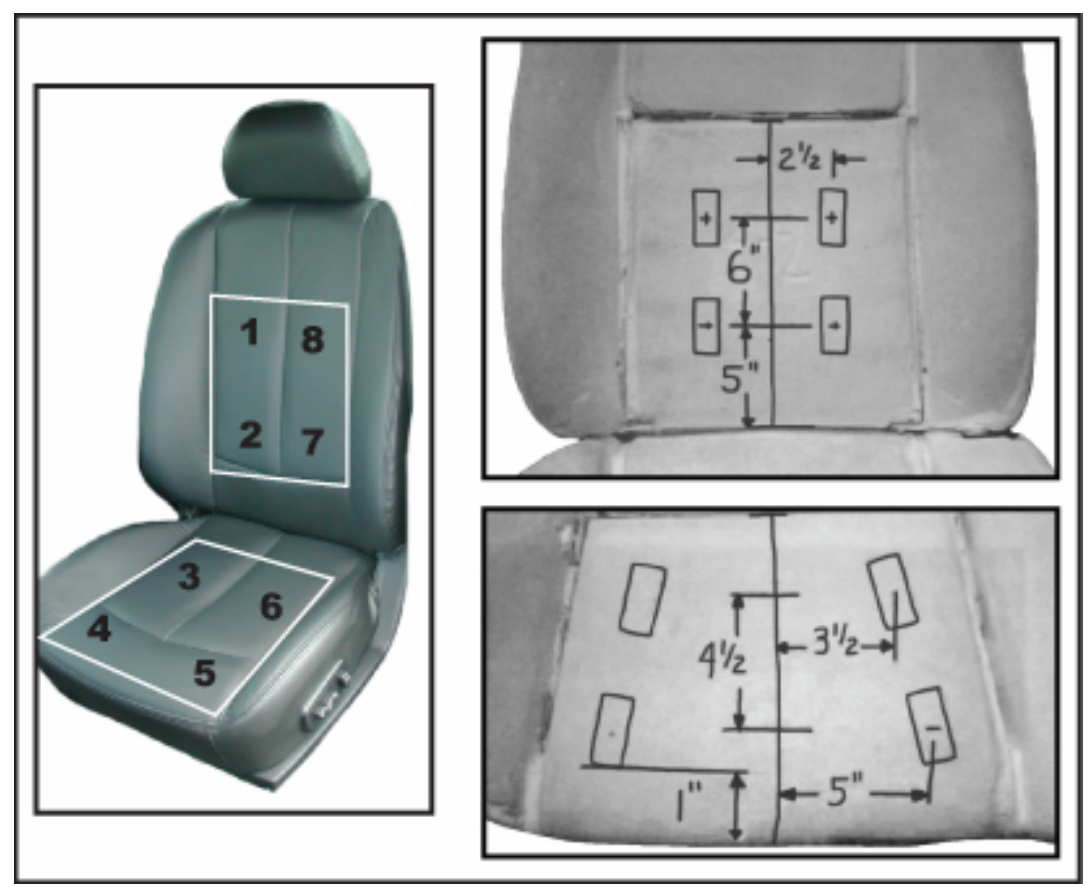

Figure 1. Haptic seat

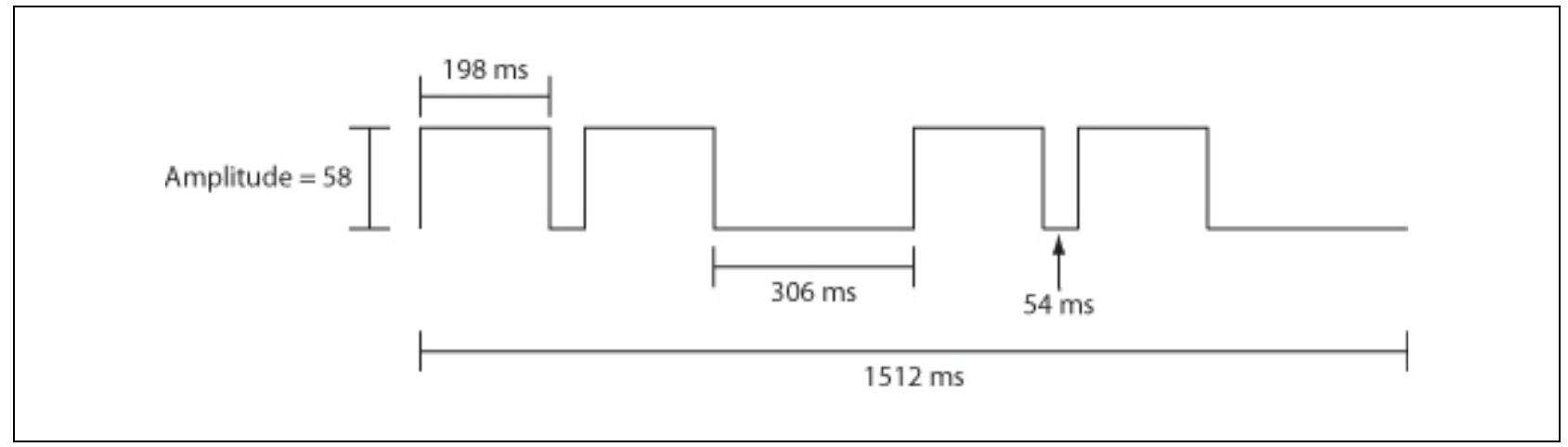

Figure 2. Haptic pulse pattern for $\mathrm{LDW}$ 


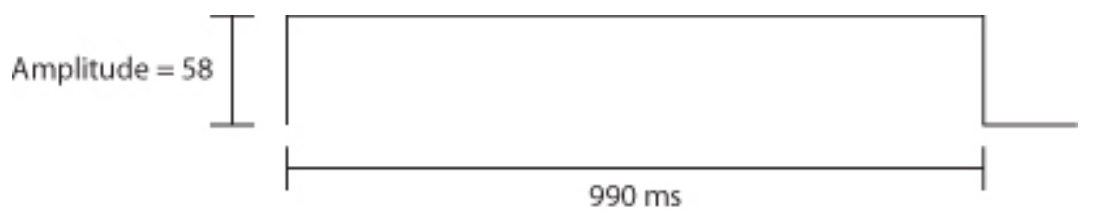

Figure 3. Haptic pulse pattern for CSW

For imminent warnings, the driver received either a warning tone intended to simulate the sound of driving over rumble strips (for LDW - Figure 4), or the words "Curve! Curve!" (for CSW Figure 5). The output level of the warning was based upon the ambient noise level, as measured in the cabin of the vehicle, and was presented at roughly $15 \mathrm{dBA}$ above ambient. Additionally, if the in-cabin noise level was sufficiently high and the radio was in use, the radio volume was reduced during the presentation of a warning, and ramped back up to the previous level upon completion.

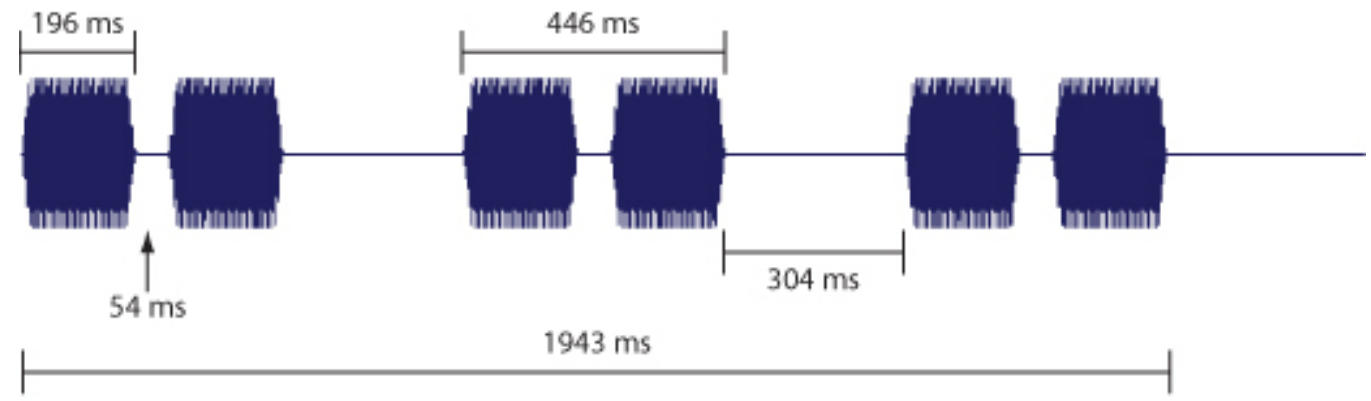

Figure 4. LDW auditory warning 


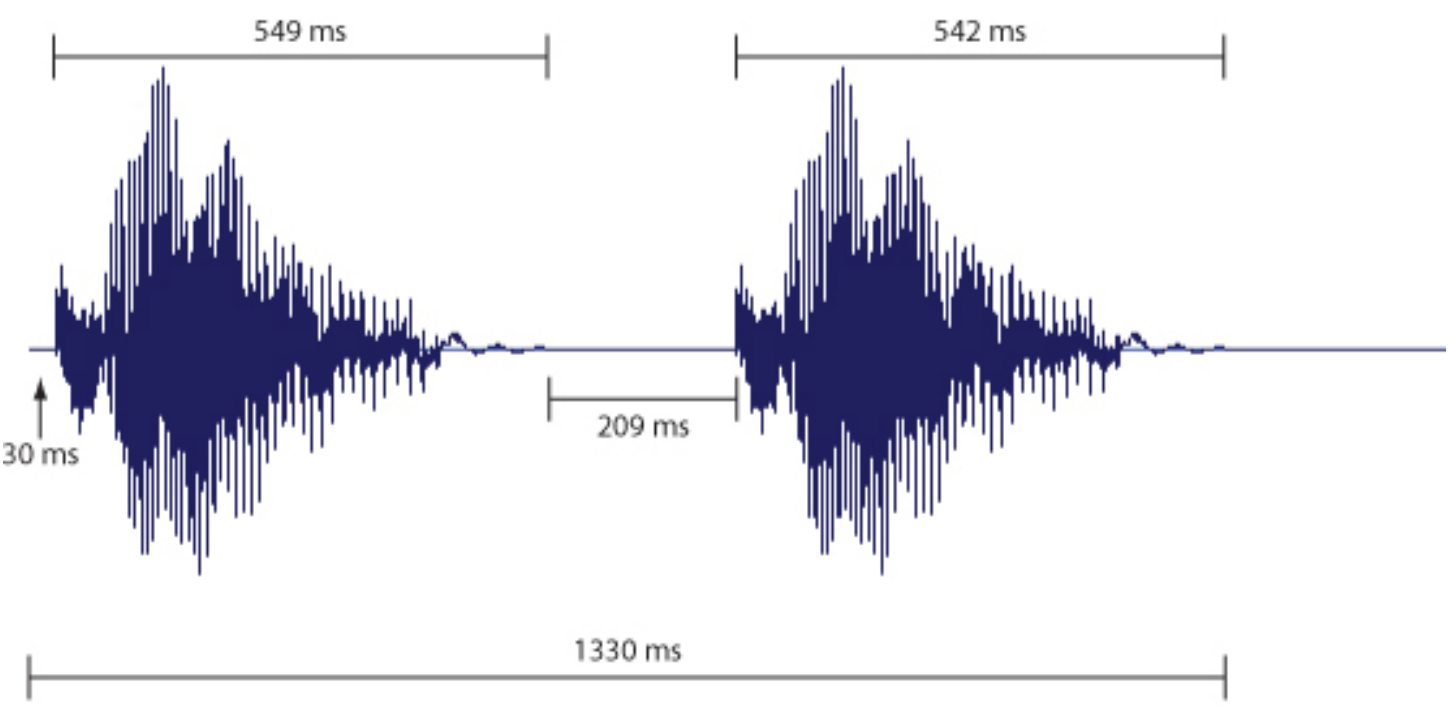

Figure 5. CSW auditory warning

\section{RESULTS}

This section details a subset of the debrief questions given to each participant. For the purposes of this data analysis, a two by two design of modality (haptic, auditory) by system (LDW, CSW) was employed. All questions were based on a 7-point scale with Strongly Disagree as the anchor for 1 and Strongly Agree as the anchor for 7. Table 1 lists the questions or statements used in the analyses. Where " $<\bmod >$ " occurs insert either haptic or auditory, where " $<$ sys $>$ " occurs insert either LDW or CSW for the permutation of the original question. Questions 1 through 4 all had 4 permutations, while the remainder only had 2 for each question.

Table 1. Questions Used in the Data Analysis

\begin{tabular}{|c|c|}
\hline 1 & The $<$ sys $><$ mod $>$ warnings got my attention. \\
\hline 2 & I knew what to do when I felt/heard the $<$ sys $><$ mod $>$ warnings. \\
\hline \multirow[t]{3}{*}{3} & I could easily recognize: \\
\hline & A) that the $<$ sys $><\bmod >$ warning was/were coming from $<$ location $>$. \\
\hline & B) which $<$ location $>$ the $<$ sys $><\bmod >$ warnings were being presented. \\
\hline 4 & The $<$ mod or sys $><$ mod or sys $>$ warnings were not distracting. \\
\hline 7 & Overall, I could easily identify the urgency of the $<$ sys $>$ warnings. \\
\hline 8 & I could easily distinguish between the $<\bmod >$ warnings (when the systems are combined). \\
\hline 9 & I understood the meaning and required response of each $<\bmod >$ warning when they occurred. \\
\hline 10 & $\begin{array}{l}\text { It was easy for me to recognize what warning condition the overall system was attempting to convey from } \\
\text { the }<\bmod >\text { warnings. }\end{array}$ \\
\hline 11 & $\begin{array}{l}\text { If passengers did comment on the auditory }<\text { sys }>\text { warnings, what kinds of comments were made? } \\
\text { (Open ended) }\end{array}$ \\
\hline
\end{tabular}


For question 3, "I could easily recognize the location of the warning," modality was significant $\left(F_{3}(1,302)=6.772, p=0.010\right)$, with the location, or directionality, of the haptic warning being more easily recognized than auditory. $\operatorname{System}\left(F_{3}(1,302)=6.772, p=0.010\right)$ was also significant, with CSW more easily recognized in terms of location. The interaction of modality and system was also significant $\left(F_{3}(1,302)=6.772, p=0.010\right)$; LDW auditory warnings had the lowest rating while CSW auditory had the highest.

When participants were asked if they agreed with the following statement, "The $<$ mod $><$ sys $>$ warnings were not distracting," modality was significant $\left(F_{4}(1,304)=4.698, p=0.031\right)$, with haptic warnings being less distracting than auditory.

Auditory warnings were rated significantly higher than haptic when participants were asked if they could easily distinguish between the lateral drift and curve speed warnings $\left(F_{8}(1,144)=\right.$ $8.816, p=0.003)$ and what warning condition the overall system was attempting to convey $\left(F_{10}(1,144)=5.273, p=0.023\right)$.

For the statement, "The $<$ sys $><\bmod >$ warnings got my attention," modality was not found to be significant, but system was significant with LDW being rated highest $\left(F_{l}(1,304)=4.533, p=\right.$ 0.034).

No significant results were found for questions 2, 7 or 9; "I knew what to do when I felt/heard the warning," "I could easily identify the urgency of the warnings," and "I understood the meaning and required response of the warnings when they occurred."

Because the statistical results are not as conclusive as one might hope, the participants' comments were examined for further insight into drivers' preference of auditory versus haptic warnings. When asked if passengers in the vehicle commented on the LDW system, the comment, "What was that?" was the most frequent followed by "That's annoying." Some people commented about the utility of the system itself, "That's pretty cool," and "That would be good for older people." Lastly, for LDW, probably due to the warning being a tone, passengers wanted to know if everything was OK ("Are we going to crash?", "Is it broke?"). For CSW, the comments were slightly different. The first two categories, "What was that?" and "That's annoying" were the same. However, apparently laughter was also a common response, as it was next in terms of frequency. Unlike LDW, there were no comments about whether the car was OK. For both systems, surprisingly, there were few comments regarding the actual driving performance, as noted by one participant: "Never had anyone sigh with relief that I was being warned to slow down." On the other hand, as can be expected, for the haptic warnings passengers rarely commented on the warning itself and it was usually not considered negative.

The haptic warnings did suffer from a few drivers being unable to differentiate the lateral localization for the LDW and the front localization for the CSW, as indicated by comments such as, "It felt like the whole seat buzzed," and "I couldn't tell which leg was being vibrated." 


\section{CONCLUSIONS}

Each modality had its bright spots. For haptic, the fact that these warnings do not alert the entire car was a positive. It will not "make the baby cry" as one participant stated the auditory warnings did. Nor did it tempt passengers to comment on the driver's behavior "HAHAHA. You're going off the road again," or provide comic relief, "Dada, did your car say Urve?" Participants also considered haptic to be less distracting than auditory warnings. On the other hand, auditory warnings provided for better recognition between alerts. And lastly, although important, for auditory warnings, the participants had a better understanding of the meaning and the required response for each warning than for the haptic warnings.

From the subjective reports alone, it is difficult to determine which modality is better for either LDW or CSW. There is an inherent confound in the design of this warning strategy in that haptic is only assigned to the cautionary warnings and auditory only to the imminent warnings, further complicating the issue. Analyses of the objective measures to determine how the drivers reacted physically to the warnings (e.g., for LDW lane offset after warning and for CSW speed after warning) must be performed to aid in the decision regarding the optimal modality selection.

\section{REFERENCES}

Lerner, N. D., Kotwal, B. M., Lyons, R. D., and Gardner-Bonneau, D. J. (1996). Preliminary human factors guidelines for crash avoidance warning devices (Report No. DOT HS 808 342). Washington, DC: U.S. Department of Transportation.

Koopman, J. A. and Najm, W. G., (2002). Analysis of off-roadway crash countermeasures for intelligent vehicle applications (Report No. 2002-01-0396). Warrendale, PA: Society of Automotive Engineers.

Najm, W. G., Sen, B., Smith, J. D., and Campbell, B. N. (2003). Analysis of light vehicle crashes and pre-crash scenarios based on the 2000 General Estimates System (Report No. DOT HS 809 573). Washington. DC: U.S. Department of Transportation. 